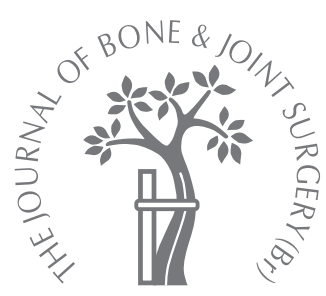

N. J. Little, V. Verma, C. Fernando, D. S. Elliott, A. Khaleel

From St Peter's Hospital, Chertsey, England

N. J. Little, MRCS, MSc, Specialist Registrar in Trauma and Orthopaedics

Orthopaedic and Trauma Unit Waikato Hospital, Pembroke Street, Hamilton, New Zealand.

V. Verma, MS, MRCS,

Research Fellow, Trauma and

Orthopaedics

C. Fernando, MRCS,

Registrar, Trauma and

Orthopaedics

D. S. Elliott, FRCS(Orth),

Consultant, Trauma and

Orthopaedics

In. Khaleel, MSc, FRCS(Orth),

Consultant, Trauma and

Orthopaedics

Rowley Bristow Orthopaedic

Unit

Ashford \& St Peters Hospital,

Guilford Road, Chertsey,

Surrey, KT16 OPZ, UK.

Correspondence should be sent to $\mathrm{Mr} \mathrm{N}$. J. Little; e-mail:

njlittle@gmail.com

(C)2008 British Editorial Society of Bone and Joint Surgery doi:10.1302/0301-620X.90B8 $20825 \$ 2.00$

$J$ Bone Joint Surg [Br] 2008;90-B:1073-8.

Received 30 January 2008;

Accepted after revision 10 April 2008

\title{
A prospective trial comparing the Holland nail with the dynamic hip screw in the treatment of intertrochanteric fractures of the
}

hip

We compared the outcome of patients treated for an intertrochanteric fracture of the femoral neck with a locked, long intramedullary nail with those treated with a dynamic hip screw (DHS) in a prospective randomised study.

Each patient who presented with an extra-capsular hip fracture was randomised to operative stabilisation with either a long intramedullary Holland nail or a DHS. We treated 92 patients with a Holland nail and 98 with a DHS. Pre-operative variables included the Mini Mental test score, patient mobility, fracture pattern and American Society of Anesthesiologists grading. Peri-operative variables were anaesthetic time, operating time, radiation time and blood loss. Post-operative variables were time to mobilising with a frame, wound infection, time to discharge, time to fracture union, and mortality.

We found no significant difference in the pre-operative variables. The mean anaesthetic and operation times were shorter in the DHS group than in the Holland nail group (29.7 vs 40.4 minutes, $p<0.001$; and 40.3 vs 54 minutes, $p<0.001$, respectively). There was an increased mean blood loss within the DHS group versus the Holland nail group $(160 \mathrm{ml} v \mathrm{~s}$ $78 \mathrm{ml}$, respectively, $p<0.001$ ). The mean time to mobilisation with a frame was shorter in the Holland nail group (DHS 4.3 days, Holland nail 3.6 days, $p=0.012$ ). More patients needed a post-operative blood transfusion in the DHS group ( 23 vs seven, $p=0.003$ ) and the mean radiation time was shorter in this group (DHS 0.9 minutes vs Holland nail 1.56 minutes, $p<$ 0.001). The screw of the DHS cut out in two patients, one of whom underwent revision to a Holland nail. There were no revisions in the Holland nail group. All fractures in both groups were united when followed up after one year.

We conclude that the DHS can be implanted more quickly and with less exposure to radiation than the Holland nail. However, the resultant blood loss and need for transfusion is greater. The Holland nail allows patients to mobilise faster and to a greater extent. We have therefore adopted the Holland nail as our preferred method of treating intertrochanteric fractures of the hip.

The debate continues about how best to treat extra-capsular fractures of the hip. Operative fixation remains the mainstay of treatment. In theory, there is an advantage to using an intramedullary device as it reduces the bending moment across the implant/fracture construct. $^{1,2}$ The most recent Cochrane review states that, given the higher overall complication rate associated with intramedullary devices, the sliding hip screw is, or appears to be, a better method of treating intertrochanteric hip fractures. ${ }^{1}$

A variety of intramedullary devices have been used. Their complications are welldocumented and include fracture below the stem, failure of fixation, and the complications of distal locking. ${ }^{1,3-6}$ The use of a trochantericentry nail has been shown to reduce the risk of fracture of the neck and upper part of the femur. ${ }^{7,8}$ However, most of the literature to date has compared short intramedullary devices with the sliding hip screw. ${ }^{8-12}$

The use of a long trochanteric-entry nail in the low-energy subtrochanteric fracture has been shown to have an acceptable level of post-operative complications and give a favourable functional outcome. ${ }^{13}$ However, to our knowledge, there are no prospective randomised trials that compare the functional outcome of patients with an intertrochanteric hip fracture treated by fixation with a long trochanteric-entry intramedullary nail or a dynamic hip screw (DHS; Biomet, Swindon, United Kingdom).

The Holland nail (Biomet) is a trochantericentry point femoral nail. It has a proximal diameter of $13 \mathrm{~mm}$ and the long nail is avail- 


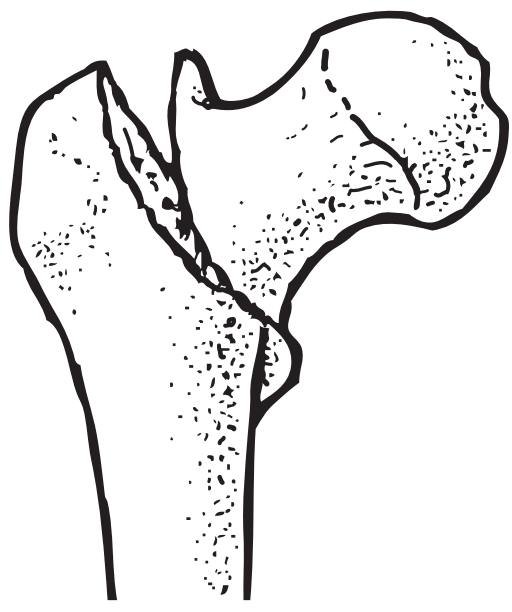

A1

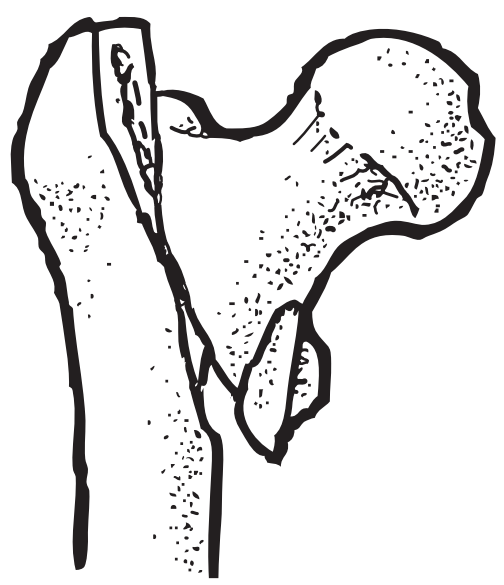

A2

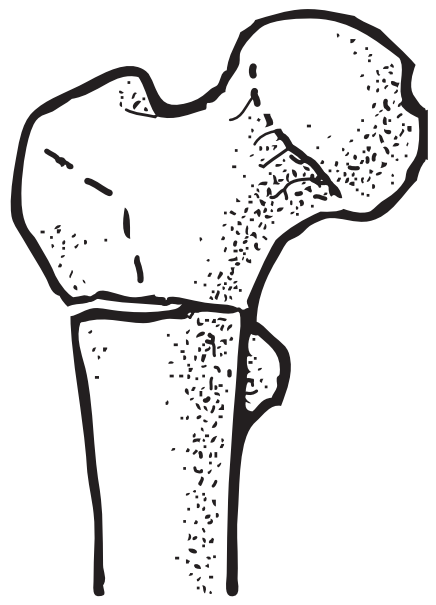

A3

Fig. 1

$\mathrm{AO}$ classification of intertrochanteric hip fractures.

able with a $9 \mathrm{~mm}$ or $12 \mathrm{~mm}$ distal diameter. It can be locked proximally into the femoral neck with two $7 \mathrm{~mm}$ partiallythreaded cannulated screws to achieve rotational stability and distally with two $4 \mathrm{~mm}$ static locking partiallythreaded bolts.

The aim of treating an intertrochanteric hip fracture is to produce a stable construct that allows early mobilisation and weight-bearing but with minimal complications. The hypothesis of this study was that patients mobilise faster after a Holland nail than after a DHS. Their operation time, intra-operative blood loss, imaging time, rate of wound infection, time to fracture union and mobility after one year were also compared.

\section{Patients and Methods}

Following approval from the local ethics committee, each patient who presented to the Accident and Emergency department with an extracapsular fracture of the neck of the femur was evaluated for inclusion in this study. We included any patient with a low-energy extracapsular intertrochanteric fracture. The fractures were graded using the $\mathrm{AO} /$ Association for the Study of Internal Fixation (ASIF) classification (A1-3) (Fig. 1). ${ }^{14}$ Only those with a subtrochanteric extension of the fracture were excluded.

After giving informed consent, patients were allocated a sequential study number and were randomised by computer to be treated either with a DHS or a Holland nail. The pre- and post-operative care was the same for both groups. There were no exclusions after randomisation.

A total of 190 patients were enrolled, 92 in the Holland nail group and 98 in the DHS group. There were 84 women in the Holland nail group and 78 in the DHS group (Table I).
Pre-operative care and variables. Each patient was made as fit as possible before their operation. Their fitness for surgery was independently assessed by the consultant anaesthetist who was administering the anaesthetic. The individual patient American Society of Anaesthesiologists (ASA) score, ${ }^{15}$ Mini Mental test score ${ }^{16}$ and pre-admission mobility were recorded. Mobility was assessed using the Parker and Palmer mobility score (Table II). ${ }^{17}$

Intra-operative care. Each patient was given a single-dose antibiotic teicoplanin (Aventis Pharma, Kings Hill, United Kingdom) and gentamicin at induction. The method of anaesthesia was either regional, regional and general, or general. The anaesthetic was given by a specialist registrar or consultant anaesthetist. The total time of anaesthesia was recorded from entry to the anaesthetic room to entry to the operating theatre.

Patients were then transferred to a traction table where closed reduction of the fracture was carried out. A standard operative technique either recommended by the manufacturer or by previous studies was used. ${ }^{14,18}$ The length of the Holland nail was measured from the tip of the greater trochanter to the superior pole of the patella before skin incision and confirmed intra-operatively. Each procedure was carried out by a specialist registrar under supervision or by a consultant who was familiar with both procedures. The length of the operation, total radiation time and blood loss were recorded. The length of the operation from skin incision to skin closure was recorded. Dynamic hip screw isolation drapes (Ioban Steri-drape, Bracknell, United Kingdom) were used as an aid to accurate assessment of the intra-operative blood loss. The total blood loss was calculated by adding the volume of blood on the swabs to that in the drapes. This was independently assessed and recorded by the anaesthetist. 
Table I. Overall patient demographics

\begin{tabular}{|c|c|c|c|}
\hline & Total & Holland nail & Dynamic hip screw \\
\hline Number of patients & 190 & 92 & 98 \\
\hline Female & 157 & 84 & 78 \\
\hline Male & 28 & 8 & 20 \\
\hline Mean age in yrs (range) & 83.4 (50 to 102$)$ & 82.6 (54 to 102$)$ & $84.2(50$ to 98$)$ \\
\hline \multicolumn{4}{|l|}{ Side of fracture (\%) } \\
\hline Left & $98(51.6)$ & $47(51.1)$ & $51(52.0)$ \\
\hline Mean mini Mental test score (SD) & $7.8(2.8)$ & $8.1(2.8)$ & $7.5(2.7)$ \\
\hline Mean pre-operative mobility (SD) & $6.2(2.8)$ & $6.5(2.7)$ & $5.8(2.8)$ \\
\hline \multicolumn{4}{|l|}{ Fracture type (\%) } \\
\hline $\mathrm{A} 1$ & $44(23.2)$ & $15(16.3)$ & $29(29.6)$ \\
\hline $\mathrm{A} 2$ & $89(46.8)$ & $38(41.3)$ & $51(52.0)$ \\
\hline A3 & $57(30)$ & $39(42.4)$ & $18(18.4)$ \\
\hline \multicolumn{4}{|c|}{ American Society of Anesthesiologists Score (\%) } \\
\hline 1 & $5(2.6)$ & $2(2.2)$ & $3(3.1)$ \\
\hline 2 & $112(58.9)$ & $57(62.0)$ & $55(56.1)$ \\
\hline 3 & $70(36.8)$ & $33(35.8)$ & $37(37.7)$ \\
\hline 4 & $3(1.7)$ & $0(0.0)$ & $3(3.1)$ \\
\hline
\end{tabular}

Table II. Parker and Palmer mobility score $(0 \text { to } 9)^{17}$

\begin{tabular}{lllll}
\hline & No problem & With aids & With help from another person & Unable to perform \\
\hline Able to get about the house & 3 & 2 & 1 & 0 \\
Able to get out of the house & 3 & 2 & 1 & 0 \\
Able to go shopping & 3 & 2 & 1 & 0 \\
\hline
\end{tabular}

Post-operative care. Appropriate prophylaxis against infection (teicoplanin and gentamicin for 24 hours after surgery) and thromboembolism was routinely given to all patients. Low-risk patients were given $150 \mathrm{mg}$ aspirin once daily for six weeks, whereas high-risk patients received low-molecular-weight $40 \mathrm{mg}$ subcutaneous heparin once daily while in hospital, then $150 \mathrm{mg}$ aspirin once daily after discharge for six weeks. Pain relief was standardised.

Patients received a blood transfusion if their haemoglobin fell below $8 \mathrm{~g} / \mathrm{dl}$ or if they became symptomatic with a haemoglobin level between $8 \mathrm{~g} / \mathrm{dl}$ and $10 \mathrm{~g} / \mathrm{dl}$.

The patient's wounds were inspected on the first and seventh days by an independent surgeon. Any oozing wounds were swabbed and those that were infected were classified using established guidelines ${ }^{19}$ and treatedwith the appropriate antibiotics for five to seven days.

Patients were mobilised fully weight-bearing on the first post-operative day. Their rehabilitation was standardised regardless of the type of fixation used. The time taken to mobilise with a frame and duration of hospital stay were independently assessed and recorded.

Follow-up was at six weeks, six months and one year post-operatively. Plain anteroposterior and lateral radio- graphs were taken at each visit and reviewed for fracture union or implant failure. The patient's mobility at one year was assessed using the Parker and Palmer mobility score. ${ }^{17}$

Statistical analysis. Statistical analysis was performed using SPSS for Windows (SPSS Inc., Chicago, Illinois). Using time taken to mobilise with a frame as a primary outcome measure, a sample size of 80 in each group was needed to show a $20 \%$ difference $(\alpha=0.05 ; \beta=0.80$; SD 0.5 of mean). Additional patients were recruited to allow for possible attrition. The unpaired independent $t$ test was used to compare study outcome measures with parametric means. The chi-squared test and Fisher's exact test were used to compare non-parametric means. The level of significance was set at $\mathrm{p}<0.05$.

\section{Results}

The 30-day mortality was similar for both the Holland nail and DHS groups (seven patients $(7.6 \%)$ vs six patients $(6.1 \%)$, respectively and no patient was lost to follow-up (Fig. 2). At one year, 76 patients were reviewed in the Holland nail group and 80 in the DHS group. The demographic and pre-operative variables of the two groups were comparable (Table I). 


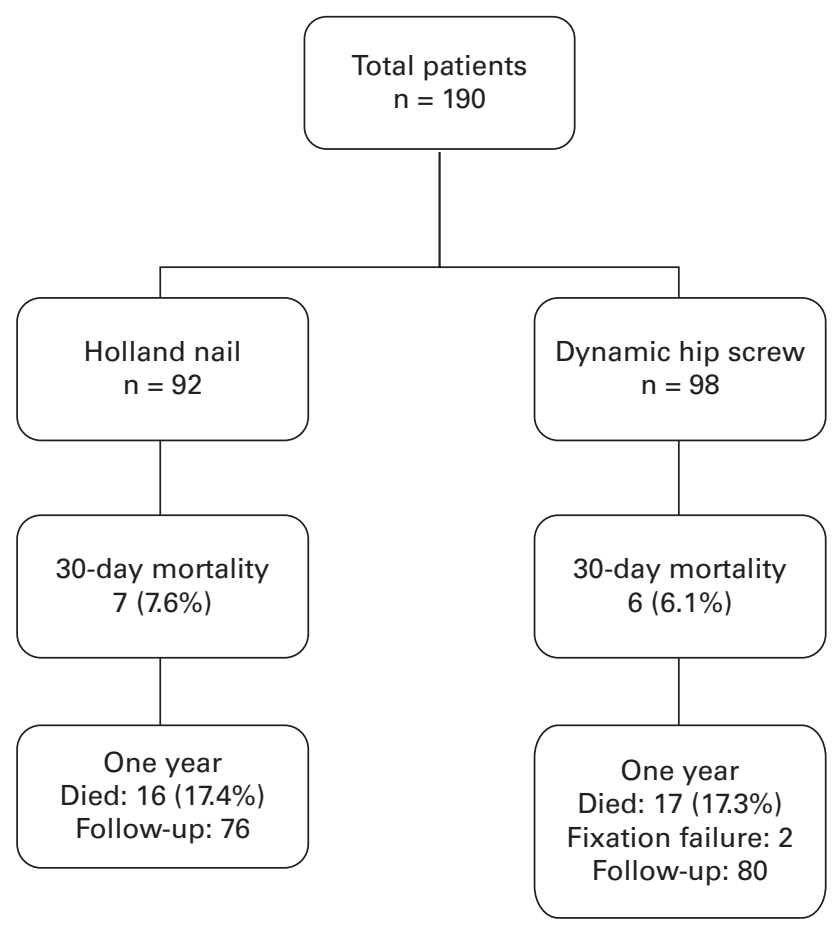

Fig. 2

Flow diagram showing 30-day mortality and one-year follow-up in the two groups.

We found no difference in the type of anaesthesia given to each group. However, the mean anaesthetic and operation times were longer in the Holland nail group (40.4 vs 29.7 minutes, $\mathrm{p}<0.001$, and 54 vs 40.3 minutes, $\mathrm{p}<0.001$, respectively). There was significantly increased mean blood loss in DHS group $(160 \mathrm{ml}$ vs $78 \mathrm{ml}$, respectively, $\mathrm{p}<0.001$ ) and more patients needed a post-operative blood transfusion in the DHS group (23 vs seven, $\mathrm{p}=0.003)$. The mean radiation time was significantly longer in the Holland nail group (1.56 min vs 0.9 min, $\mathrm{p}<$ 0.001). All results are shown in Table III.

There were more wound infections requiring antibiotics in the DHS group (ten patients $v s$ five), although the difference was not statistically significant $(p=0.286)$. No wound was re-opened, and all had healed after six weeks. There was one patient with a deep-vein thrombosis in the DHS group who was treated with warfarin for six months. No patient had a pulmonary embolus, but 13 (six Holland nail, seven DHS) developed a post-operative chest infection which required treatment with antibiotics. One patient in the DHS group had a transient ischaemic attack. There were two implant failures $(2 \%)$ in the DHS group, one of which was revised to a Holland nail 12 days after the index DHS procedure and this patient was excluded from the one-year analysis. The proximal screws migrated laterally in four patients $(4.3 \%)$ with a Holland nail: all were treated conservatively. There was no significant difference in implant failures between the groups. No proximal or distal femoral fracture was noted in the Holland nail group.

The mean time to mobilisation with a frame was significantly shorter in the Holland nail group (3.6 vs 4.3 days, $\mathrm{p}=0.012)$. After one year, every fracture had united. Patients who had a Holland nail were significantly more mobile than those with a DHS (mobility score: 5.9 vs 3.8, $\mathrm{p}<0.001)$ and were more likely to regain their pre-operative mobility score (49 patients $v s 30$ patients, $\mathrm{p}<0.001$ ).

\section{Discussion}

The best treatment of extracapsular hip fractures remains a matter for debate. In 2005, the Cochrane review compared a variety of implants used to treat these fractures. ${ }^{1}$ They found that a Gamma nail performed no better than a DHS, and recommended the DHS as the implant of choice on the basis of the higher level of complications with the Gamma nail. Moreover, they found no advantage in using a proximal femoral nail for these fractures.

The Holland nail is similar to the proximal femoral nail in having two proximal locking screws. It differs in its proximal diameter $(13 \mathrm{~mm} v s 15 \mathrm{~mm})$ and the size of the locking screws. In this study, each patient in the Holland nail group received a long distally-locked nail (Fig. 3). These have previously been used to treat subtrochanteric and high-energy proximal femoral fractures to good effect. ${ }^{9,13,20}$ To the best of our knowledge, no previous study has assessed the use of the Holland nail in the treatment of intertrochanteric fractures.

There are two previous controlled studies comparing the mobility of patients treated with a proximal femoral nail or a DHS. Pajarinen et $\mathrm{al}^{21}$ randomised 108 patients with lowenergy extracapsular pertrochanteric fractures to have either a proximal femoral nail or a DHS. After four months, they found that patients in the proximal femoral nail group were more likely to have regained their preoperative level of mobility than those in the DHS group. However, their ability to walk was the same. They suggested that the impaction of the fracture in the DHS group led to femoral neck shortening and a mechanical disadvantage compared with the proximal femoral nail. Conversely, Saudan et $\mathrm{al}^{10}$ reported a reduction in mobility after one year in patients treated with a proximal femoral nail compared with those treated with a DHS. Our study shows that one year after the index operation, patients who received a Holland nail were $50 \%$ more mobile than those with a DHS. Moreover, $64 \%$ of patients in the Holland nail group regained their pre-fracture mobility, compared with $37 \%$ in the DHS group.

This is in line with previous studies of the proximal femoral nail and Gamma nail, which reported a restoration of mobility in $40 \%$ to $70 \%$ of patients. ${ }^{8,11,21}$ However, our study uses a more comprehensive system for measuring mobility. Fogagnolo et $\mathrm{al}^{12}$ have shown that only $32 \%$ recover their Parker and Palmer mobility score four months after a proximal femoral nail. The Holland nail is similar to 
Table III. Intra- and post-operative variables in the two groups

\begin{tabular}{|c|c|c|c|}
\hline & Holland nail & DHS & p-value \\
\hline \multicolumn{4}{|l|}{ Type of anaesthetic } \\
\hline General & 7 & 10 & $>0.5$ \\
\hline Regional & 68 & 69 & $>0.5$ \\
\hline Other & 17 & 19 & $>0.5$ \\
\hline Mean total anaesthetic time in mins $\left(95 \% \mathrm{Cl}^{*}\right)$ & 40.4 (35.4 to 45.3$)$ & $29.7(26.9$ to 32.4$)$ & $<0.001$ \\
\hline Mean operative time in mins $(95 \% \mathrm{Cl})$ & $54 \quad$ (49.3 to 58.7$)$ & 40.3 (37.3 to 43.2 ) & $<0.001$ \\
\hline Mean intra-operative blood loss in $\mathrm{ml}(95 \% \mathrm{Cl})$ & $78 \quad$ (51 to 104$)$ & $160 \quad(125$ to 196$)$ & $<0.001$ \\
\hline Mean radiation time in mins $(95 \% \mathrm{Cl})$ & 1.56 (1.3 to 1.8$)$ & $0.9(0.7$ to 1.0$)$ & $<0.001$ \\
\hline Patients receiving blood transfusions (\%) & $7(7.6)$ & $23(23.5)$ & 0.003 \\
\hline Time to frame in days $(95 \% \mathrm{Cl})$ & 3.6 (3.3 to 3.9 ) & 4.3 (3.9 to 4.8$)$ & 0.012 \\
\hline Patients with wound infections (\%) & $5(5.4)$ & $10(10.2)$ & 0.286 \\
\hline Mobility at one year $(95 \% \mathrm{Cl})$ & 5.9 (5.3 to 6.5$)$ & 3.8 (3.3 to 4.3 ) & $<0.001$ \\
\hline Patients with mobility restored at one year (\%) & $49(64)$ & $30(37)$ & $<0.001$ \\
\hline
\end{tabular}

* $95 \% \mathrm{Cl}, 95 \%$ confidence interval

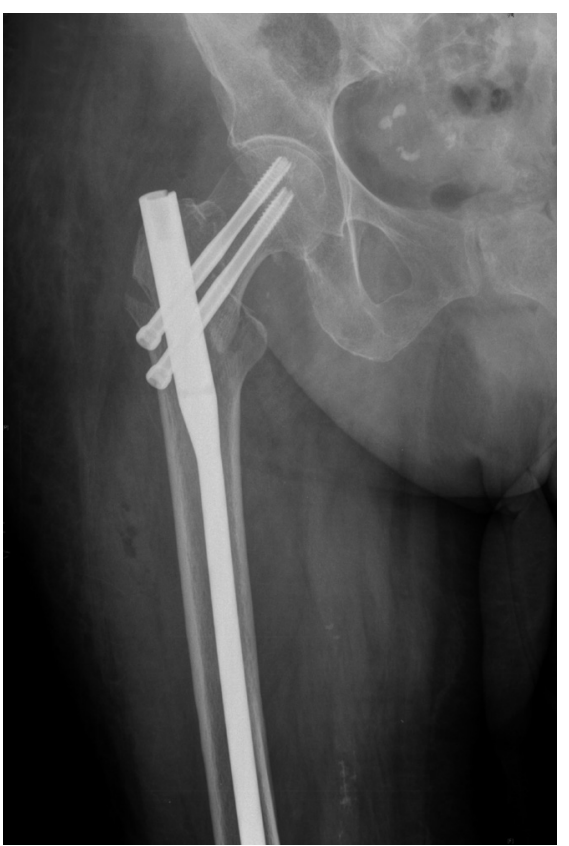

Plain radiographs demonstrating a right intertrochanteric fracture treated with a Holland nail. the proximal femoral nail, and although the one-year radiographs were not assessed for shortening of the femoral neck or shaft, it would seem reasonable that the improvement in mobility can be attributed to improved restoration of hip anatomy and biomechanics.

Our study also shows that the time taken to mobilise with a frame is shorter with the Holland nail than with the DHS. The reason for this may be any combination of postoperative factors: pain, muscle dysfunction and medical comorbidities. The Holland nail is implanted through a

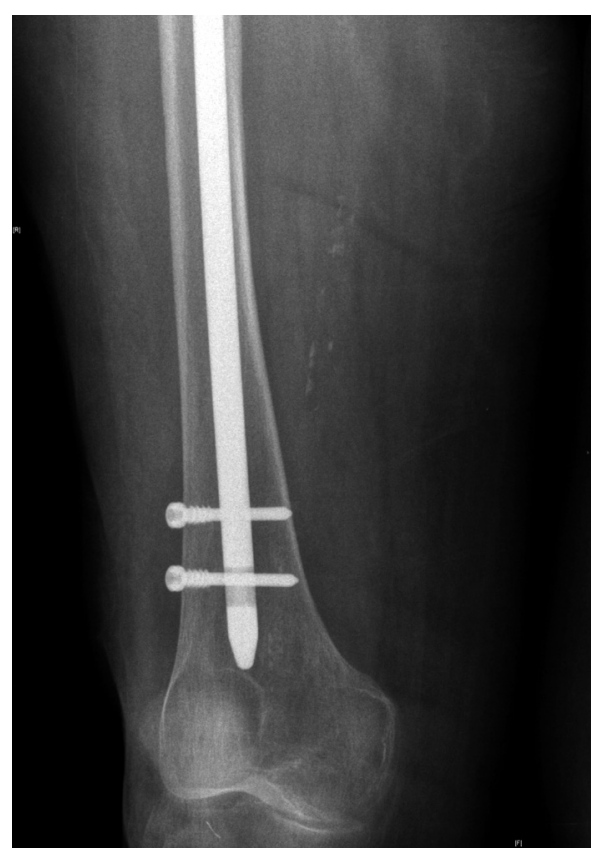

Fig. 3 small incision above the greater trochanter. This entry point causes less damage to the superior gluteal nerve and gluteus medius muscle than other entry points in the piriform fossa. ${ }^{22}$ The DHS, however, requires a larger incision and probably damages more muscle. We also found a doubling of the intra-operative blood loss when using the DHS and three times as many patients needed a blood transfusion, which slowed their mobilisation.

The anaesthetic, operating and radiation times were longer in the Holland nail group. This may be a function of the 
learning curve in its use, but we were unable to compare the grade of doctor with the duration of the procedure because of the small sample size. There were also more superficial and deep infections in the DHS group (DHS, ten $v$ s Holland nail, five), but this did not reach statistical significance $(\mathrm{p}=0.286)$. There were no post-operative femoral fractures in either group, and only one DHS was revised for implant failure.

There are several limitations to this study. Post-operative pain was not measured in every patient and is, therefore, not presented. This was because of the varied mental capacity of patients within each group (Mini-Mental test scores ranging from 0 to 10 for both groups). Although every radiograph was examined for component failure, measurements of the femoral neck and shaft were not recorded. This may have provided further evidence to support the improved post-operative mobility seen in the Holland nail group. The sample size was estimated using mobility as the primary outcome measure. Larger sample sizes would be needed to provide useful subgroup analysis. There were, in addition, more A3 fractures in the Holland nail group. There was no bias to place patients with A3 fractures in this group, and the small numbers of each fracture type may account for this difference.

This study shows that the Holland nail can be used safely to treat all intertrochanteric fractures. It has a low rate of complications and allows patients to mobilise more quickly and to a higher level than the DHS. It is now the implant of choice in our unit.

No benefits in any form have been received or will be received from a commercial party related directly or indirectly to the subject of this article.

\section{References}

1. Parker MJ, Handoll HH. Gamma and other cephalocondylic intramedullary nails versus extramedullary implants for extracapsular hip fractures in adults. Cochrane Database Syst Rev 2005;4:CD000093.

2. FriedI W, Clausen J. Experimental examination for optimized stabilisation of trochanteric femur fractures, intra- or extramedullary implant localisation and influence of femur neck component profile on cut-out risk. Chirurg 2001;72:1344-52 (in German).

3. Parker MJ, Handoll HH. Intramedullary nails for extracapsular hip fractures in adults. Cochrane Database Syst Rev 2006;3:CD004961.
4. Albareda J, Laderiga A, Palanca D, Paniagua L, Seral F. Complications and technical problems with the gamma nail. Int Orthop 1996;20:47-50.

5. Bridle SH, Patel AD, Bircher M, Calvert PT. Fixation of intertrochanteric fractures of the femur: a randomised prospective comparison of the gamma nail and the dynamic hip screw. J Bone Joint Surg [Br] 1991;73-B:330-4.

6. Aune AK, Ekeland A, Odegaard B, et al. Gamma nail vs compression screw for trochanteric femoral fractures: 15 reoperations in a prospective, randomized study of 378 patients. Acta Orthop Scand 1994;65:127-30.

7. Herrera A, Domingo J, Martinez A. Results of osteosynthesis with the ITST nail in fractures of the trochanteric region of the femur. Int Orthop 2007; E-pub (ahead of print).

8. Herrera A, Domingo LJ, Calvo A, Martínez A, Cuenca J. A comparative study of trochanteric fractures treated with the Gamma nail or the proximal femoral nail. Int Orthop 2002;26:365-9.

9. Sehat K, Baker RP, Pattison G, et al. The use of the long gamma nail in proximal femoral fractures. Injury 2005;36:1350-4.

10. Saudan M, Lübbeke A, Sadowski C, et al. Pertrochanteric fractures: is there an advantage ot an intramedullary nail?: a randomized, prospective study of 206 patients comparing the dynamic hip screw and proximal femoral nail. J Orthop Trauma 2002;16:386-93

11. Domingo LJ, Cecilia D, Herrera A, Resines C. Trochanteric fractures treated with a proximal femoral nail. Int Orthop 2001;25:298-301.

12. Fogagnolo F, Kfuri M Jr, Paccola CA. Intramedullary fixation of pertrochanteric hip fractures with the short A0-ASIF proximal femoral nail. Arch Orthop Trauma Surg 2004;124:31-7.

13. Robinson CM, Houshian S, Khan LA. Trochanteric-entry long cephalomedullary nailing of subtrochanteric fractures caused by low-energy trauma. J Bone Joint Surg [Am] 2005;87-A:2217-26.

14. Hoffman R, Haas NP. Femur: proximal. In: Ruedi, Murphy WM, eds. AO principles of fracture management. Stuttgart, etc: Thieme, 2000:441-54.

15. No authors listed. American Society of Anesthiologists Classification System. http:// www.asahq.org/clinical/physicalstatus.htm (date last accessed 24 June 2008).

16. Folstein MF, Folstein SE, McHugh PR. "Mini-metal state": a practical method for grading the cognitive state of patients for the clinician. J Psychiatr Res 1975;12:189-98.

17. Parker MJ, Palmer CR. A new mobility score for predicting mortality after hip fracture. J Bone Joint Surg [Br] 1993;75-B:797-8.

18. Biomet UK. Intramedullary nails: Holland Nail system; surgical technique. http:// www.biomet.com/templates/btbs/prf/fixation/holland.pdf 2002.

19. Horan TC, Gaynes RP, Martone WJ, Jarvis WR, Emori TG. CDC definitions of nosocomial surgical site infections, 1992: a modification of CDC definitions of surgical wound infections. Infect Control Hosp Epidemiol 1992;13:606-8.

20. Hamilton RJ, Kelly IG. Evaluation of the long intra-medullary hip screw. Injury 2004;35:1264-9.

21. Pajarinen J, Lindahl $J$, Michelsson 0 , Savolainen $V$, Hirvensalo $E$. Pertrochanteric femoral fractures treated with a dynamic hip screw or a proximal femoral nail: a randomised study comparing post-operative rehabilitation. J Bone Joint Surg [Br] 2005;87-B:76-81.

22. Moein CM, Verhofstad MH, Bleys RL, van der Werken C. Soft tissue injury related to choice of entry point in antegrade femoral nailing: piriform fossa or greater trochanter tip. Injury 2005;36:1337-42. 